\title{
Work Outcomes in Patients Who Stay at Work Despite Musculoskeletal Pain
}

\author{
Andy Cochrane ${ }^{1} \cdot$ Niamh M. Higgins ${ }^{2} \cdot$ Conor Rothwell ${ }^{1}$. Jennifer Ashton ${ }^{3} \cdot$ Roisin Breen $^{4} \cdot$ Oriel Corcoran $^{5}$. \\ Oliver FitzGerald ${ }^{6} \cdot$ Pamela Gallagher $^{7}$. Deirdre Desmond ${ }^{1}$
}

Published online: 13 December 2017

(C) Springer Science+Business Media, LLC, part of Springer Nature 2017

\begin{abstract}
Purpose To assess self-reported work impacts and associations between psychosocial risk factors and work impairment amongst workers seeking care for musculoskeletal pain while continuing to work. Methods Patients were recruited from Musculoskeletal Assessment Clinics at 5 hospitals across Ireland. Participants completed questionnaires including assessments of work impairment (Work Productivity and Activity Impairment Questionnaire), work ability (single item from the Work Ability Index) and work performance (Work Role Functioning Questionnaire; WRFQ). Logistic and hierarchical regressions were conducted to analyse the relation between psychosocial variables and work outcomes. Results 155 participants $(53.5 \%$ female; mean age $=46.50$ years) who were working at the time of assessment completed the questionnaires. Absenteeism was low, yet $62.6 \%$ were classified as functioning poorly according to the WRFQ; $52.3 \%$ reported having poor work ability. Logistic regression analyses indicated that higher work role functioning was associated with higher pain self-efficacy (OR 1.51); better work ability was associated with older age (OR 1.063) and lower functional restriction (OR 0.93); greater absenteeism was associated with lower pain self-efficacy (OR 0.65) and poorer work expectancy (OR 1.18). Multiple regression analysis indicated that greater presenteeism was associated with higher pain intensity $(\beta=0.259)$ and lower pain self-efficacy $(\beta=-0.385)$. Conclusions While individuals continue to work with musculoskeletal pain, their work performance can be adversely affected. Interventions that target mutable factors, such as pain self-efficacy, may help reduce the likelihood of work impairment.
\end{abstract}

Keywords Disability $\cdot$ Musculoskeletal pain $\cdot$ Psychosocial risk factors $\cdot$ Work functioning

Andy Cochrane

andy.cochrane@mu.ie

1 Department of Psychology, Maynooth University, Co Kildare, Ireland

2 Department of Psychology, Anglia Ruskin University, Cambridge, UK

3 Physiotherapy Services, Beaumont Hospital, Dublin, Ireland

4 Royal College of Physicians in Ireland, Dublin, Ireland

5 Rheumatology Services, University Hospital Waterford, Waterford, Ireland

6 School of Medicine, St. Vincent's University Hospital, Elm Park, Dublin 4, Ireland

7 School of Nursing and Human Sciences, Dublin City University, Dublin, Ireland

\section{Introduction}

Musculoskeletal disorders (MSDs) are the leading cause of temporary and permanent work related disability across Europe [1]. Work disability is conceptualized as a complex interaction among biological, physical, behavioural/ psychological, and social phenomena [2,3]. A particular focus has been on the psychosocial factors (i.e. yellow flags), which may influence the transition to persistent pain, chronicity, absenteeism and disability [4, 5]. Research to date has tended to concentrate on the association between psychosocial variables and work-related outcomes in individuals already off work with long-lasting MSDs [6] and the majority of intervention studies for MSDs have focused on reducing sickness absence and facilitating return to work $[7,8]$. Reductions in psychosocial risk factors have been associated with higher probability of return to work in people with chronic MSD (e.g. 
$[9,10])$. A systematic review of biopsychosocial predictors of prognosis in MSDs indicated that recovery expectations (including pain self-efficacy and perceived work capacity), and the availability of work place accommodations were predictive of work participation [2].

Less is known about workers who are occupationally active with MSDs and who may be at risk of reduced productivity or work ability, and associated downstream effects $[6,11]$. There is some evidence that psychosocial factors are associated with staying at work and maintaining good work ability [12, 13]. For example, a systematic review concluded that, although the level of evidence was low, staying at work was associated with low perceived physical disability and low emotional distress; while duration of pain, catastrophizing, self-esteem and marital status were not associated with staying at work [13]. Differences between those with MSD who stay at work compared to those who are sick listed have also been documented in fear-avoidance, pain acceptance, pain catastrophizing, pain self-efficacy, life control and perceived physical workload [6]. Furthermore, amongst patients seeking physical therapy delivered in primary care, high pain self-efficacy and low fear avoidance characterised those continuing to work with musculoskeletal pain, compared to those who were no longer working [14].

Workers may alter their hours of work or duties to accommodate their pain and reduce the impact of MSD [15], but a proportion of workers with recurrent or persistent MSDs will have difficulties in maintaining their occupational performance [16]. Reduced work ability and/ or experiences of work instability, "a mismatch between an individual's functional and/or cognitive abilities and the demands of the job" (p. 350; [17]) can have a negative impact on productivity at work [18] as well as leading to sickness absence and ultimately job loss [19]. Loss of productivity at work has been reported for a range of MSDs [20]. The relationship between worker health and presenteeism is probably highly contextual [21] as there are likely to be interactions between psychosocial factors, the specific demands of an occupation [22], job accommodations and episodes of recurrence of MSD [21]. Understanding the association between psychosocial risk factors and work ability in those individuals who stay at work despite their MSD, could help in ensuring that employees are appropriately managed and supported to remain working [16].

The current cross-sectional study assesses the impact of MSDs on self-reported work outcomes amongst workers seeking treatment for their MSDs while continuing to work. In addition, the study aims to examine the association between psychosocial risk factors and work impairment.

\section{Methods}

\section{Participants}

Participants were recruited to the study by Clinical Specialist Physiotherapists (CSPs) at Musculoskeletal Assessment Clinics in five hospitals across the Republic of Ireland. Clinical Specialist Musculoskeletal Physiotherapists were introduced to the Irish healthcare system in 2012 under the National Clinical Care Programmes for Rheumatology and Orthopaedics to triage patients on out-patient waiting lists and improve long term musculoskeletal referral management. Patients are referred from primary care to orthopaedic and rheumatology consultants and, where indicated, triaged to CSP led Musculoskeletal Assessment Clinics. The initiative has been successful in managing waiting lists while maintaining high patient satisfaction ratings [23]. Patients were eligible for inclusion if they were: aged at least 18 years; first time referrals to the triage clinic; diagnosed with regional musculoskeletal pain; in paid employment at time of assessment (full- or parttime); and had sufficient spoken and written English for the demands of the study. Patients with inflammatory conditions (e.g. rheumatoid arthritis, connective tissue diseases and psoriatic arthritis), and those requiring surgical interventions were excluded. The current analyses are restricted to participants who were had worked at least some of the time during the 4 weeks preceding assessment.

\section{Procedure}

Patients who were new referrals for assessment at the Musculoskeletal Assessment Clinic were screened by the CSP for study eligibility when they presented for their clinic appointment. Those meeting the study inclusion criteria were given written information about the study and invited to take part. Prior to completing the questionnaire participants signed an informed consent form. Information pertaining to each participant's waiting time (i.e., time from referral by their general practitioner to assessment by the CSP), diagnosis, and assessment outcome (e.g., referral to physiotherapy, referral to occupational therapy) was documented by the CSP. Ethical approval to carry out the study was granted by the Research Ethics Committee at each participating hospital and by the University Research Ethics Committee.

\section{Measures}

Participants provided information on socio-demographic characteristics including sex, age, marital status, educational 
attainment, current/most recent occupation, work (i.e. working full-time, part-time) and insurance status.

Pain-related psychosocial factors were assessed using the Örebro Musculoskeletal Pain Screening Questionnaire (OMPSQ [24]). This measure consists of 25 items, 21 of which are used in scoring; items are summed to give a total score ranging from 3 to 210 . The items are grouped into six subscales to assess functional restrictions (4 items), pain (3 items), distress ( 2 items), fear-avoidance ( 3 items), work expectancy (3 items) and coping (1 item) [25]. Subscale scores have been used to predict treatment outcomes [26, 27] sick leave [28], disability [25] and return to work [29].

Pain catastrophizing was assessed using the Pain Catastrophizing Scale (PCS [30]). The 13 items describe thoughts and feelings related to pain (e.g., "I worry all the time about whether the pain will end" and "I anxiously want the pain to go away"). Items are scored on a five-point scale ranging from 0 (not at all) to 4 (all the time), with higher scores indicating a greater tendency towards catastrophizing; items are summed to yield a total score (range 0-52) [30].

Pain self-efficacy was assessed using the Pain SelfEfficacy Questionnaire short form (PSEQ-2 [31]) which assesses beliefs in the ability to carry out activities when experiencing pain. Two items: "I can do some form of work despite the pain" ("work" includes housework and paid and unpaid work) and "I can live a normal lifestyle despite the pain" are rated on 7-point scales ranging from 0 (not at all confident) to 6 (completely confident). Items are summed to yield a total score; higher scores indicate greater perceived pain self-efficacy, with a range of $0-12$.

\section{Work-Related Variables}

Two items, adapted from a study by Tillett et al. [32], assessed whether the employer knew of the participant's MSD and their helpfulness concerning the participant's pain-related needs: "Does (or did) your employer know about your musculoskeletal pain/condition?" (yes/no) and "If your employer is/was aware of your musculoskeletal pain/condition", how helpful are/were they with your painrelated needs at work (scored on a 5-point scale: $1=$ very unhelpful to $5=$ very helpful), with an option of "no help needed'.

A single item from the Work Ability Index (WAI [33]) was used to assess perceptions of current workability compared to lifetime best on a 10 -point scale $(0=$ completely unable to work to $10=$ work ability at its best). This single item has been shown to have a strong correlation with the total scale and to be a strong predictor of the future degree of sick leave and health-related quality of life [34]. A cut-off score of $\geq 8$ has been used to distinguish between high and low work ability [35, 36].
Absenteeism and impairment in work and non-work activities during the preceding week, resulting from the respondent's health condition was assessed by the Work Productivity and Activity Impairment Questionnaire (specific health problem version) (WPAI: SHP [37]). The WPAI consists of six items from which four main outcome scores expressed as percentages can be derived: work time missed (absenteeism); impairment while working (presenteeism); overall work impairment; and activity impairment. Higher values indicate greater impairment and less productivity.

The Work Role Functioning Questionnaire 2.0 (WRFQ [35]) consists of 27 items assessing perceived difficulties among employees in meeting work demands due to their physical health or emotional problems. The measure is divided into four subscales: Work scheduling and output demands; Physical demands; Mental \& Social demands; and Flexibility demands. For each item, the participant is asked to indicate the percentage of time difficulties were experienced when performing job demands with responses ranging from 0 (difficult all of the time, 100\%) to 4 (difficult none of the time, $0 \%$ ). Total work role functioning scores are calculated by averaging responses and are transformed so that higher total scores indicate better work functioning; scores greater than 90 are considered to indicate 'good work functioning', while a score 95-100 is indicative of 'successful work functioning' [35].

\section{Statistical Analyses}

Data analyses were performed using IBM SPSS 21.0. The following approach was employed where missing data occurred: for ÖMSPQ, WRFQ, and PCS where a minimum of $80 \%$ of the items were answered, mean item scores were imputed to replace missing values to allow for calculation of scale scores. Where fewer than $80 \%$ of items were answered, a total score was not calculated. For PSE and WPAI, total scores were calculated only for participants who answered all items. In line with previous research [32], the absenteeism item from the WPAI was dichotomised with participants being grouped according to whether they missed any time from work or not. Descriptive statistics (frequencies, means, standard deviations, and range) were calculated for socio-demographic and psychosocial variables. Associations between potential explanatory variables and work outcomes were examined using stepwise backward logistic regression (absenteeism, WPAI; work role functioning, WRFQ (total scores); work ability, WAI) and hierarchical multiple regression (presenteeism; WPAI). The number of candidate variables $(n=12)$ raised issues around type I and type II errors. For logistic regressions, a stepwise backward entry method was preferred to the use of Bonferroni corrections as the best way to reduce both type I and type II errors. For multiple regression (with listwise deletion), candidate predictor 
variables were selected for inclusion based on correlations with target dependent variable (presenteeism). A correlation of 0.3 or higher qualified candidate variables for inclusion. Candidate predictor variables were age, gender, the ÖMSPQ subscales (pain, function, psychological distress, fear avoidance, coping and work expectancy), pain self-efficacy and pain catastrophizing, number of pain sites and employer knowledge of participants MSD.

\section{Results}

Data were collected between October 2015 and June 2016. Of the participants who completed the questionnaire $(n=162), 155$ were actively working in the 4 weeks prior to the clinic assessment (data regarding the number of patients who met the inclusion criteria but who declined to take part in the study were not available). Descriptive data for socio-demographic characteristics and clinical outcomes (diagnosis, treatment outcomes) are reported in Table 1. Participants were employed primarily in manual occupations (68\%). Over half $(\mathrm{n}=79 ; 51 \%)$ reported pain duration of more than 1 year, most of the participants $(115 ; 74 \%)$ had taken $<15$ days sick leave due to their MSD over the previous year; $14(9 \%)$ were currently on sick leave. Half of the patients $(n=84 ; 54 \%)$ reported that their employer knew about their MSD; 59\% of these $(n=51)$ indicated that their employer was helpful/very helpful in meeting their pain related needs at work.

\section{Psychosocial and Work Variables}

Descriptive statistics for the psychosocial and work variables are presented in Table 2 . The mean work ability level (WAI) was 6.88 (SD 2.28), with $52.3 \%$ of the sample reporting poor work ability $(<8)$. Absenteeism, as measured by the WPAI, was relatively low with participants missing an average of $6.9 \%$ (SD 17.8\%) of work hours the previous week, while $60 \%$ of participants reported no absenteeism during that period. Presenteeism was more prevalent with participants reporting an average of 32.5\% (SD 29.2\%) reduction in productivity while at work the previous week (Table 2). The mean WRFQ total score suggests that the participants were only meeting the demands of the job $61.5 \%$ of the time (SD $28.55)$, with most difficulty in meeting physical demands. Ninety-seven (62.6\%) participants scored $<90$, the criterion for "poor work functioning".

\section{Associations with Work Ability and Work Role Functioning}

Two separate logistic regressions were conducted to explore the relationship between (1) work ability and (2) work
Table 1 Demographic and clinical characteristics

\begin{tabular}{|c|c|c|}
\hline \multirow{2}{*}{$\frac{\text { Variables }}{\text { Female }}$} & \multicolumn{2}{|c|}{$\mathrm{n}=155$} \\
\hline & 83 & $(53.5 \%)$ \\
\hline Age mean (range; SD) years & 46.50 & $(20-71 ; 11.33)$ \\
\hline \multicolumn{3}{|l|}{ Marital status } \\
\hline Married/living with a partner & 88 & $(56.7 \%)$ \\
\hline Single & 33 & $(21.3 \%)$ \\
\hline Other & 20 & $(12.8 \%)$ \\
\hline \multicolumn{3}{|l|}{ Highest level of education completed } \\
\hline Primary & 11 & $(7.1 \%)$ \\
\hline Secondary & 81 & $(52.3 \%)$ \\
\hline University & 61 & $(39.4 \%)$ \\
\hline \multicolumn{3}{|l|}{ Self-employed } \\
\hline Yes & 13 & $(8.4 \%)$ \\
\hline \multicolumn{3}{|l|}{ Type of work } \\
\hline Manual & 105 & $(67.7 \%)$ \\
\hline Non-manual & 43 & $(27.7 \%)$ \\
\hline \multicolumn{3}{|l|}{ Work circumstances } \\
\hline Full-time & 94 & $(60.6 \%)$ \\
\hline Part-time (<30 h/week) & 57 & $(36.8 \%)$ \\
\hline Hours reduced due to pain & 17 & $(11.0 \%)$ \\
\hline Currently on sick leave & 14 & $(9.0 \%)$ \\
\hline Employer aware of MSD (yes) & 84 & $(54.2 \%)$ \\
\hline Very helpful & 25 & $(29.1 \%)$ \\
\hline Helpful & 26 & $(30.2 \%)$ \\
\hline No help needed & 14 & $(16.3 \%)$ \\
\hline Unhelpful & 8 & $(9.3 \%)$ \\
\hline Very unhelpful & 11 & $(12.8 \%)$ \\
\hline \multicolumn{3}{|l|}{ Number of sites of pain (patient rated) } \\
\hline Single site & 78 & $(50.3 \%)$ \\
\hline Two sites & 27 & $(17.4 \%)$ \\
\hline Three sites & 20 & $(13.9 \%)$ \\
\hline$\geq$ Four sites & 23 & $(14.8 \%)$ \\
\hline \multicolumn{3}{|c|}{ Primary site of MSK complaint (CSP rated) } \\
\hline Spinal & 29 & $(18.7 \%)$ \\
\hline Upper limb & 47 & $(30.3 \%)$ \\
\hline Lower limb & 49 & $(31.6 \%)$ \\
\hline Other & 5 & $(3.2 \%)$ \\
\hline $\begin{array}{l}\text { Time from referral to Review by CSP } \\
\text { (range; SD) weeks }\end{array}$ & 27.21 & $(3-104 ; 19.50)$ \\
\hline \multicolumn{3}{|l|}{ Treatment } \\
\hline Further investigations & 27 & $(17.4 \%)$ \\
\hline Physiotherapy & 61 & $(39.4 \%)$ \\
\hline Injection $^{\mathrm{b}}$ & 15 & $(9.7 \%)$ \\
\hline Occupational therapy & 3 & $(1.9 \%)$ \\
\hline Orthopaedic consultant & 11 & $(7.1 \%)$ \\
\hline \multicolumn{3}{|l|}{ Duration of pain problem $^{a}$} \\
\hline$<5$ weeks & 7 & $(4.5 \%)$ \\
\hline 5-23 weeks & 18 & $(11.6 \%)$ \\
\hline 24-35 weeks & 20 & $(12.9 \%)$ \\
\hline $36-52$ weeks & 28 & $(18.1 \%)$ \\
\hline$>52$ weeks & 79 & $(51.0 \%)$ \\
\hline
\end{tabular}


Table 1 (continued)

\begin{tabular}{|c|c|c|}
\hline Variables & \multicolumn{2}{|c|}{$\mathrm{n}=155$} \\
\hline \multicolumn{3}{|c|}{ Days off work due to pain in last year ${ }^{\mathrm{a}}$} \\
\hline None & 65 & $(41.9 \%)$ \\
\hline $1-14$ days & 50 & $(32.2 \%)$ \\
\hline 15-30 days & 11 & $(7.1 \%)$ \\
\hline $31-90$ & 17 & $(11.0 \%)$ \\
\hline$>90$ & 4 & $(2.5 \%)$ \\
\hline \multicolumn{3}{|c|}{ Health insurance/medical card } \\
\hline Private health insurance & 28 & $(18.1 \%)$ \\
\hline Medical card ${ }^{\mathrm{c}}$ & 50 & $(32.3 \%)$ \\
\hline Both & 2 & $(1.3 \%)$ \\
\hline Neither & 61 & $(39.4 \%)$ \\
\hline
\end{tabular}

Percentages are calculated based on $n=155$, where total percentage does not sum to $100 \%$ missing data occurred

${ }^{\mathrm{a}}$ From Örebro Musculoskeletal Screening Questionnaire

bJoint or soft tissue injection (steroid with/without local anaesthetic)

${ }^{\mathrm{c}}$ Entitlement to free medical services with eligibility based on financial means

role functioning and potential predictor variables (demographic, psychosocial) (Table 3). For work ability, the full model was statistically significant, $\chi^{2}(3, n=107)=30.99$, $\mathrm{p}<0.001$, indicating that the model was able to distinguish between participants who reported poor/moderate or good/ excellent work ability. The model explained between $25.1 \%$ (Cox and Snell $\mathrm{R}^{2}$ ) and 33.6\% (Nagelkerke $\mathrm{R}^{2}$ ) of the variance in work ability, and correctly classified $74.8 \%$ of cases (Hosmer and Lemeshow $\mathrm{p}=0.916$ ). In the final model two variables were statistically significant. Good/excellent work ability was associated with functional restriction (OR 0.929; 95\% CI 0.883-0.977; $\mathrm{p}=0.004$ ), and age (OR 1.063; 95\% CI 1.018-1.109; $\mathrm{p}=0.005)$. Lower functional restriction and older age increased the odds of being classified as being in the good/excellent work ability group.

For work role functioning, the full model was statistically significant, $\chi^{2}(4, \mathrm{n}=94)=25.479, \mathrm{p}<0.001$, indicating that the model was able to distinguish between participants classified as good $(>90)$ or poor functioning $(\leq 90)$. The model explained between $23.7 \%$ (Cox and Snell $\mathrm{R}^{2}$ ) and $35.0 \%$ (Nagelkerke $\mathrm{R}^{2}$ ) of the variance in work role functioning, and correctly classified $78.7 \%$ of cases (Hosmer and Lemeshow $\mathrm{p}=0.826$ ). Good work role functioning was explained by pain self-efficacy (OR 1.514; 95\% CI 1.088-2.107; $\mathrm{p}=0.014$ ). Higher self-efficacy was associated with good work role functioning.

\section{Associations with Absenteeism and Presenteeism}

For absenteeism, the full model was statistically significant, $\chi^{2}(3, \mathrm{n}=86)=26.281, \mathrm{p}<0.001$, indicating that the model
Table 2 Psychosocial and work outcomes

\begin{tabular}{|c|c|c|c|c|}
\hline \multirow[t]{2}{*}{ Variables } & \multicolumn{4}{|c|}{$\mathrm{n}=155$} \\
\hline & M & $(\mathrm{SD})$ & $\mathrm{n}$ & $(\%)$ \\
\hline ÖMSPQ (total score) & 93.75 & 29.68 & & \\
\hline \multicolumn{5}{|l|}{ ÖMSPQ subscales } \\
\hline Pain (3 items) & 17.51 & $(6.74)$ & & \\
\hline Coping (1 item) & 5.06 & $(2.63)$ & & \\
\hline Distress (2 items) & 7.24 & $(5.45)$ & & \\
\hline Work expectancy (3 items) & 11.06 & $(5.06)$ & & \\
\hline Fear and avoidance (3 items) & 16.77 & $(7.57)$ & & \\
\hline Functional restriction (5 items) & 15.58 & $(10.70)$ & & \\
\hline Pain self efficacy (PSEQ-2) & 8.72 & $(2.57)$ & & \\
\hline Pain catastrophizing (PCS) & 16.01 & $(12.17)$ & & \\
\hline WAI & 6.88 & $(2.28)$ & & \\
\hline$<8$ (medium/poor) & & & 81 & $(52.3 \%)$ \\
\hline 8-10 (good/excellent) & & & 71 & $(45.8 \%)$ \\
\hline \multicolumn{5}{|l|}{ WPAI (\%) } \\
\hline Overall impairment & 32.52 & $(29.16)$ & & \\
\hline Absenteeism & 6.88 & $(17.79)$ & & \\
\hline Number reporting no sick leave & & & 93 & $(60.0 \%)$ \\
\hline Presenteeism & 32.52 & $(29.16)$ & & \\
\hline Productivity loss outside of work & 36.57 & $(27.8)$ & & \\
\hline \multicolumn{5}{|l|}{ WRFQ (\%) } \\
\hline Total score & 61.47 & $(28.55)$ & & \\
\hline$<90$ (poor functioning) & & & 97 & $(62.6 \%)$ \\
\hline Work scheduling & 59.14 & $(32.73)$ & & \\
\hline Physical & 51.33 & (31.23) & & \\
\hline Mental and social & 65.53 & $(33.56)$ & & \\
\hline Flexibility & 66.55 & $(36.05)$ & & \\
\hline
\end{tabular}

ÖMSPQ Örebro Musculoskeletal Screening Questionnaire (range 3-210), WAI Work Ability Index (range 0-10), WPAI Work Productivity and Activity Impairment Questionnaire (range 0-100\%), WRFQ Work Role Functioning Questionnaire (range 0-100\%)

was able to distinguish between participants who were absent in the previous week (Table 3). The model explained between 26.3\% (Cox and Snell R ${ }^{2}$ ) and $41 \%$ (Nagelkerke $\mathrm{R}^{2}$ ) of the variance in absenteeism (Hosmer and Lemeshow $\mathrm{p}=0.67$ ), and correctly classified $83.7 \%$ of cases. In the final model two variables explained significant unique variance. Absenteeism was explained by pain self-efficacy (OR 0.650; 95\% CI 0.466-0.908; $\mathrm{p}=0.012)$, and work expectancy (OR $1.179 ; 95 \%$ CI 1.006-1.382; $\mathrm{p}=0.042$ ). Those with lower pain self-efficacy and poorer work expectancies were more likely to report absences in the previous week.

A hierarchical multiple regression was used to assess the ability of demographic and psychosocial variables (age, sex, pain, distress, work expectancy, fear and avoidance, functional restriction, pain self-efficacy, pain catastrophizing) to predict levels of presenteeism in the sample (Table 4). Age and gender were entered at step 
Table 3 Logistic regression analyses with work ability, work role functioning, and absenteeism as dependent variables

\begin{tabular}{|c|c|c|c|c|c|c|c|c|c|}
\hline & \multicolumn{3}{|c|}{$\begin{array}{l}\text { Work ability (poor/moderate vs. good/ } \\
\text { excellent) }\end{array}$} & \multicolumn{3}{|c|}{ Work role functioning (good vs. poor) } & \multicolumn{3}{|c|}{$\begin{array}{l}\text { Absenteeism (absence in previous } \\
\text { week vs. no absence) }\end{array}$} \\
\hline & Odds ratio & $95 \% \mathrm{CI}$ & $p$ value & Odds ratio & $95 \% \mathrm{CI}$ & $p$ value & Odds ratio & $95 \% \mathrm{CI}$ & $p$ value \\
\hline Age & 1.063 & (1.063-1.018) & 0.005 & & & & & & \\
\hline Sex $($ female $=1)$ & & & & & & & 0.310 & $(0.084-1.144)$ & 0.079 \\
\hline $\begin{array}{l}\text { Employer knowledge } \\
\quad(\text { employer aware }=1)\end{array}$ & & & & 2.813 & $(0.953-8.308)$ & 0.061 & & & \\
\hline Coping & & & & 1.201 & $(0.964-1.496)$ & 0.103 & & & \\
\hline Work expectancy & & & & 0.880 & $(0.760-1.018)$ & 0.085 & 1.179 & $(1.006-1.382)$ & 0.042 \\
\hline Fear and avoidance & 0.940 & $(0.881-1.003)$ & 0.061 & & & & & & \\
\hline Functional restriction & 0.929 & $(0.883-0.977)$ & 0.004 & & & & & & \\
\hline Pain self-efficacy & & & & 1.514 & $(1.088-2.107)$ & 0.014 & 0.650 & $(0.466-0.908)$ & 0.012 \\
\hline
\end{tabular}

Figures in bold indicate a significant unique contribution $(\mathrm{p}<0.05)$

Table 4 Multiple regression analysis with presenteeism as dependent variable

\begin{tabular}{|c|c|c|c|c|}
\hline \multirow[t]{2}{*}{ Model } & \multicolumn{4}{|c|}{ Presenteeism (linear regression) } \\
\hline & $\mathrm{R}^{2}$ & $\mathrm{R}^{2}$ change & Standardised $\beta$ & $p$ value \\
\hline 1 & 0.036 & & & \\
\hline Age & & & -0.172 & 0.057 \\
\hline Sex & & & 0.067 & 0.455 \\
\hline 2 & 0.46 & 0.424 & & \\
\hline Age & & & -0.068 & 0.351 \\
\hline Sex $($ female $=1)$ & & & 0.038 & 0.604 \\
\hline Pain & & & 0.259 & 0.004 \\
\hline Coping & & & & \\
\hline Distress & & & 0.105 & 0.230 \\
\hline Work expectancy & & & 0.038 & 0.649 \\
\hline Fear and avoidance & & & 0.022 & 0.791 \\
\hline Functional restriction & & & 0.035 & 0.729 \\
\hline Pain self-efficacy & & & -0.385 & $<0.001$ \\
\hline Pain catastrophizing & & & 0.023 & 0.819 \\
\hline
\end{tabular}

Figures in bold indicate a significant unique contribution

1 , explaining $3.6 \%$ of the variance in presenteeism levels. After the entry of the psychosocial variables (pain, distress, work expectancy, fear and avoidance, functional restriction, pain self-efficacy, pain catastrophizing) at step 2 the total variance explained by the model was $46 \%$, $\mathrm{F}(9,115)=10.90, \mathrm{p}<0.001$. The psychosocial variables explained an additional $42.4 \%$ of the variance in presenteeism, $\mathrm{R}^{2}$ change $=.424, \mathrm{~F}$ change $(7,115)=12.92$, $\mathrm{p}<0.001$. In the final model two variables made a statistically significant unique contribution, pain self-efficacy $(\beta=-0.385)$, and pain intensity $(\beta=0.259)$. Higher levels of pain and lower levels of pain self-efficacy were associated with higher rates of presenteeism.

\section{Discussion}

The aim of this study was to assess the self-reported impact of MSDs on work functioning, and explore the associations between psychosocial risk factors and work impairment in a group of workers with a range of MSDs. As might be anticipated, the current level of work ability and work functioning in people with MSDs reported was lower compared to that of a general working population [38]. Indeed, some participants in the current study perceived their work ability to be relatively poor. Overall, work ability was comparable (6.9 vs. 7.1) to that reported in an investigation of a similar cohort of active workers with chronic nonspecific musculoskeletal pain [36]. Better perceived work ability was associated with increasing age; data more typically suggest declining work ability with increased age (e.g. [39, 40]). While the reasons for this finding cannot be established in the current study, evidence from other research suggests that intrinsic motivations, including perceptions of one's own performance, increase with age [41]. In addition, it is possible that the use of coping strategies and adaptations to work tasks differs across age groups [42]. For example, the experience and skills gained at work over time may help to compensate for any changes in health or physical status [43]. Overall, the self-reported productivity losses while at work are lower than those reported in a UK study (34.29 vs. $43.9 \%$ [44]); this difference may be explained by the inclusion of the more debilitating inflammatory disorders in the UK survey. Nevertheless, the workers in our sample were reporting difficulties in meeting the demands of their job more than half of the time, with nearly two-thirds meeting the threshold for 'poor work functioning'.

Consistent with other research [14, 36, 45], high pain self-efficacy emerged as an important factor in facilitating work role functioning and maintaining productivity. Promoting self-efficacy and self-management can be key 
determinants of successful participation in the workforce providing that the workplace environment is supportive [46]. An intervention focusing on maintaining or increasing work satisfaction and job retention has been shown to be effective with employees with other long-term conditions [47]. Specifically, treatment strategies that promote mastery of functional activities and problem-solving abilities can enhance confidence and self-efficacy [14]. For most workers, firstline interventions that include reassurance about activity and work and work/workplace accommodation will be sufficient, while more structured vocational rehabilitation should be reserved for those who do not respond to conservative management [8].

It is noted that the explained variance was only moderate in this study, and the other psychosocial variables including pain catastrophizing, distress, fear and avoidance were not associated with the work measures. Importantly, the workers recruited to this study were functioning sufficiently to continue working, and this may explain why some of these risk factors, such as fear and avoidance were not significant. It seems likely that factors may become more or less pertinent at different stages in the transitions between work instability to disability [48]. Nevertheless, the inclusion of additional variables may have increased the explanatory variance for the work outcomes. For example, perceived physical workload has been associated with staying at work with MSD [6]. In addition, job control may influence self-reported workability, and promote work performance, albeit with some inconsistent findings [36].

While it is possible for people to work while experiencing some pain, this can affect an individual's productivity and quality of life [49]. Nearly half of the participants were experiencing pain in more than one joint, which may have impacted on their ability to carry out their work, especially for those with manual occupations. Indeed, higher levels of pain were associated with presenteeism. Early diagnosis is critical to ensure effective management of MSDs [50] and improve employment outcomes [49], yet participants were waiting an average of 6 months for their appointment at the assessment clinic. Even when a diagnosis is made, access to follow on investigations and treatments can be delayed [44]. While waiting for clinical interventions, the support of the workplace to maintain employment can become even more vital. Encouragingly, of those participants who indicated that their employer was aware of their MSD, nearly $60 \%$ indicated that the employer was helpful or very helpful. While employer knowledge did not reach significance in this sample, disclosure to management is likely to be an important factor in enabling positive dialogue to ensure that appropriate adjustments to work conditions and environment can be made [51, 52].

A primary limitation of the current study is the lack of data regarding response rate and associated issues of generalisability. Eligible patients were not consecutively recruited across recruitment sites and data regarding numbers potentially eligible patients were not recorded. This together with the underrepresentation of back pain patients in the sample limits the generalisability of the findings.

The benefits of staying at work, both financial and psychological are well recognised [44,53], yet the findings of this study demonstrate that, continuing to work with a MSD seems to have a cost as a proportion of workers are struggling to maintain work ability and productivity. In terms of clinical implications the findings of this study suggest that it is important for health care professionals to consider psychosocial and work-related variables when assessing workers presenting with MSDs to ensure that workers are appropriately managed, and supported to remain in employment. Equally, identifying the potentially modifiable psychosocial factors associated with staying at work, such as pain self-efficacy, could assist with the introduction of targeted interventions for those most in need.

Acknowledgements Funded by the Health Research Board [RCQPS2014-2]. We wish to acknowledge and extend our thanks to the CSPs who collaborated in recruitment and data collection.

\section{Compliance with Ethical Standards}

Conflict of interest The authors declare that they have no conflict of interest.

Ethical Approval All procedures performed in studies involving human participants were in accordance with the ethical standards of the institutional and participating hospital research committees and with the 1964 Helsinki declaration and its later amendments or comparable ethical standards.

\section{References}

1. Bevan S. Reducing temporary work absence through early intervention: the case of MSDs in the EU. London: The Work Foundation; 2013.

2. Laisné F, Lecomte C, Corbière M. Biopsychosocial predictors of prognosis in musculoskeletal disorders: a systematic review of the literature (corrected and republished). Disabil Rehabil. 2012;34(22):1912-1941.

3. Schultz IZ, Stowell AW, Feuerstein M, Gatchel RJ. Models of return to work for musculoskeletal disorders. J Occup Rehabil. 2007; 17(2):327-352.

4. Buer N, Linton SJ. Fear-avoidance beliefs and catastrophizing: occurrence and risk factor in back pain and ADL in the general population. Pain 2002;99(3):485-491.

5. Pincus TBA, Vogel S, Field AP. A systematic review of psychological factors as predictors of chronicity/disability in prospective cohorts of low back pain. Spine 2002;27(5):E109-E120.

6. de Vries HJ, Reneman MF, Groothoff JW, Geertzen JHB, Brouwer S. Workers who stay at work despite chronic nonspecific musculoskeletal pain: do they differ from workers with sick leave? J Occup Rehabil. 2012;22(4):489-502. 
7. van Vilsteren $\mathrm{M}$, van Oostrom $\mathrm{SH}$, de Vet HCW, Franche RL, Boot CRL, Anema JR. Workplace interventions to prevent work disability in workers on sick leave. Cochrane Database Syst Rev. 2015;5(10):CD006955. https://doi.org/10.1002/14651858. CD006955.pub3.

8. Cochrane A, Higgins NM, FitzGerald O, Gallagher P, Ashton J, Corcoran O, et al. Early interventions to promote work participation in people with regional musculoskeletal pain: a systematic review and meta-analysis. Clin Rehabil. 2017;31(11):1466-1481.

9. Sullivan MJ, Feuerstein M, Gatchel R, Linton SJ, Pransky G. Integrating psychosocial and behavioral interventions to achieve optimal rehabilitation outcomes. J Occup Rehabil. 2005;15(4):475-489.

10. Gauthier N, Sullivan MJL, Adams H, Stanish WD, Thibault P. Investigating risk factors for chronicity: the importance of distinguishing between return-to-work status and self-report measures of disability. J Occup Environ Med. 2006;48(3):312-318.

11. Karoly P, Ruehlman LS, Okun MA. Psychosocial and demographic correlates of employment vs disability status in a national community sample of adults with chronic pain: toward a psychology of pain presenteeism. Pain Med. 2013;14(11):1698-1707.

12. Pensola T, Haukka E, Kaila-Kangas L, Neupane S, Leino-Arjas P. Good work ability despite multisite musculoskeletal pain? A study among occupationally active Finns. Scand J Public Health 2016;44(3):300-310.

13. De Vries HJ, Reneman MF, Groothoff JW, Geertzen JHB, Brouwer S. Factors promoting staying at work in people with chronic nonspecific musculoskeletal pain: a systematic review. Disabil Rehabil. 2012;34(6):443-458.

14. Denison E, Åsenlöf P, Sandborgh M, Lindberg P. Musculoskeletal pain in primary health care: subgroups based on pain intensity, disability, self-efficacy, and fear-avoidance variables. J Pain 2007;8(1):67-74.

15. Coole C, Watson PJ, Drummond A. Staying at work with back pain: patients' experiences of work-related help received from GPs and other clinicians. A qualitative study. BMC Musculoskelet Disord. 2010;11:190. https://doi.org/10.1186/1471-2474-11-190.

16. Buck R, Wynne-Jones G, Varnava A, Main CJ, Phillips CJ. Working with musculoskeletal pain. Rev Pain 2009;3(1):6-10.

17. Gilworth G, Chamberlain MA, Harvey A, Woodhouse A, Smith J, Smyth MG, et al. Development of a work instability scale for rheumatoid arthritis. Arthritis Care Res. 2003;49(3):349-354.

18. Gilworth G, Bhakta B, Eyres S, Carey A, Anne Chamberlain M, Tennant A. Keeping nurses working: development and psychometric testing of the Nurse-Work Instability Scale (Nurse-WIS). J Adv Nurs. 2007;57(5):543-551.

19. Koolhaas W, van der Klink JJL, de Boer MR, Groothoff JW, Brouwer S. Chronic health conditions and work ability in the ageing workforce: the impact of work conditions, psychosocial factors and perceived health. Int Arch Occup Environ Health 2014;87(4):433-443.

20. McDonald M, DiBonaventura Md, Ullman S. Musculoskeletal pain in the workforce: the effects of back, arthritis, and fibromyalgia pain on quality of life and work productivity. J Occup Environ Med. 2011;53(7):765-770.

21. Beaton D, Bombardier C, Escorpizo R, Zhang W, Lacaille D, Boonen A, et al. Measuring worker productivity: frameworks and measures. J Rheumatol. 2009;36(9):2100-2109.

22. Macfarlane GJ, Pallewatte N, Paudyal P, Blyth FM, Coggon D, Crombez G, et al. Evaluation of work-related psychosocial factors and regional musculoskeletal pain: results from a EULAR Task Force. Ann Rheum Dis. 2009;68(6):885-891.

23. Ashton J, Breen R, Callanan E, FitzGerald O. Patient Satisfaction with Advanced Practice Physiotherapists (APPs) working in an extended role in Rheumatology and Orthopaedic clinics. Irish
Rheumatology Health Professionals Society Conference, Winter 20132013.

24. Linton SJ, Boersma K. Early identification of patients at risk of developing a persistent back problem: the predictive validity of the Örebro Musculoskeletal Pain Questionnaire. Clin J Pain 2003;19(2):80-86.

25. Westman A, Linton SJ, Öhrvik J, Wahlén P, Leppert J. Do psychosocial factors predict disability and health at a 3-year follow-up for patients with non-acute musculoskeletal pain? A validation of the Örebro Musculoskeletal Pain Screening Questionnaire. Eur J Pain 2008;12(5):641-649.

26. Margison DA, French DJ. Predicting treatment failure in the subacute injury phase using the Örebro Musculoskeletal Pain Questionnaire: an observational prospective study in a workers' compensation system. J Occup Environ Med. 2007;49(1):59-67.

27. Bergbom S, Boersma K, Linton SJ. Both early and late changes in psychological variables relate to treatment outcome for musculoskeletal pain patients at risk for disability. Behav Res Ther. 2012;50(11):726-734.

28. Bergström G, Hagberg J, Busch H, Jensen I, Björklund C. Prediction of sickness absenteeism, disability pension and sickness presenteeism among employees with back pain. J Occup Rehabil. 2014;24(2):278-286.

29. Hurley DA, Dusoir TE, McDonough SM, Moore AP, Baxter GD. How effective is the acute low back pain screening questionnaire for predicting 1-year follow-up in patients with low back pain? Clin J Pain. 2001;17(3):256-263.

30. Sullivan MJL, Bishop SR, Pivik J. The pain catastrophizing scale: development and validation. Psychol Assess. 1995;7(4):524-532.

31. Nicholas MK, McGuire BE, Asghari A. A 2-item short form of the Pain Self-Efficacy Questionnaire: development and psychometric evaluation of PSEQ-2. J Pain 2015;16(2):153-163.

32. Tillett W, Shaddick G, Askari A, Cooper A, Creamer P, Clunie $\mathrm{G}$, et al. Factors influencing work disability in psoriatic arthritis: first results from a large UK multicentre study. Rheumatology 2015;54(1):157-162.

33. Ilmarinen J. The Work Ability Index (WAI). Occup Med. 2007;57(2):160. https://doi.org/10.1093/occmed/kqm008.

34. Ahlstrom L, Grimby-Ekman A, Hagberg M, Dellve L. The work ability index and single-item question: associations with sick leave, symptoms, and health-a prospective study of women on long-term sick leave. Scand J Work Environ Health 2010;36(5):404-412.

35. Abma FI, Amick BC, van der Klink JJL, Bültmann U. Prognostic factors for successful work functioning in the general working population. J Occup Rehabil. 2013;23(2):162-169.

36. de Vries HJ, Reneman MF, Groothoff JW, Geertzen JHB, Brouwer S. Self-reported work ability and work performance in workers with chronic nonspecific musculoskeletal pain. J Occup Rehabil. 2013;23(1):1-10.

37. Reilly MC, Zbrozek AS, Dukes EM. The validity and reproducibility of a work productivity and activity impairment instrument. Pharmacoeconomics 1993;4(5):353-365.

38. Abma FI, van der Klink JJL, Bültmann U. The work role functioning questionnaire 2.0 (Dutch version): examination of its reliability, validity and responsiveness in the general working population. J Occup Rehabil. 2013;23(1):135-147.

39. Pohjonen T. Perceived work ability of home care workers in relation to individual and work-related factors in different age groups. Occup Med. 2001;51(3):209-217.

40. Monteiro MS, Ilmarinen J, Filho HRC. Work ability of workers in different age groups in a public health institution in Brazil. Int J Occup Saf Ergon. 2006;12(4):417-427.

41. Kooij DTAM., De Lange AH, Jansen PGW, Kanfer R, Dikkers JSE. Age and work-related motives: results of a meta-analysis. J Organ Behav. 2011;32(2):197-225. 
42. DiBonaventura MD, Gupta S, McDonald M, Sadosky A, Pettitt D, Silverman S. Impact of self-rated osteoarthritis severity in an employed population: cross-sectional analysis of data from the national health and wellness survey. Health Qual Life Outcomes 2012;10:30. https://doi.org/10.1186/1477-7525-10-30.

43. Peeters MCW, van Emmerik H. An introduction to the work and well-being of older workers: from managing threats to creating opportunities. J Manag Psychol. 2008;23(4):353-363.

44. Zheltoukhova K, O'Dea L, Bevan S. Taking the strain: the impact of musculoskeletal disorders on work and home life. London: The Work Foundation; 2012.

45. Wideman TH, Sullivan MJL. Differential predictors of the longterm levels of pain intensity, work disability, healthcare use, and medication use in a sample of workers' compensation claimants. Pain 2011;152(2):376-383.

46. Du S, Yuan C, Xiao X, Chu J, Qiu Y, Qian H. Self-management programs for chronic musculoskeletal pain conditions: a systematic review and meta-analysis. Patient Educ Couns. 2011;85(3):e299-e310.

47. Varekamp I, Heutink A, Landman S, Koning CEM, de Vries $\mathrm{G}$, van Dijk FJH. Facilitating empowerment in employees with chronic disease: qualitative analysis of the process of change. $\mathbf{J}$ Occup Rehabil. 2009;19(4):398-408.

48. Evanoff B, Dale AM, Descatha A. A conceptual model on musculoskeletal disorders for occupational health practitioners. Int J Occup Med Environ Health 2014;27(1):145-148.

49. Zheltoukhova K. Musculoskeletal Disorders and Work: results of a survey of individuals living with musculoskeletal disorders in six European countries. London: The Work Foundation; 2013.

50. Bevan S, Quadrello T, McGee R, Mahdon M, Vavrovsky A. Fit for work? Musculoskeletal disorders in the European workforce. London: The Work Foundation; 2009.

51. Shaw WS, Linton SJ, Pransky G. Reducing sickness absence from work due to low back pain: how well do intervention strategies match modifiable risk factors?. J Occup Rehabil. 2006;16(4):591-605.

52. Oakman J, Kinsman N, Briggs AM. Working with persistent pain: an exploration of strategies utilised to stay productive at work. $\mathrm{J}$ Occup Rehabil. 2017;27(1):4-14.

53. Howard KJ, Mayer TG, Gatchel RJ. Effects of presenteeism in chronic occupational musculoskeletal disorders: stay at work is validated. J Occup Environ Med. 2009;51(6):724-731. 